\title{
DECLIVE DEL LIDERAZGO DE EE. UU. CON TRUMP Y ASCENSO DE CHINA COMO OPCIÓN DEL MULTILATERALISMO GLOBAL
}

Jaime Torres ${ }^{(a)}$

\author{
DECLINE IN US LEADERSHIP UNDER TRUMP ADMINISTRATION AND \\ RISE OF CHINA AS AN OPTION FOR GLOBAL MULTILATERALISM \\ DECLÍNIO DA LIDERANÇA DOS EUA COM TRUMP E A ASCENSÃO \\ DE CHINA COMO OPÇÃO DO MULTILATERALISMO GLOBAL
}

Fecha de recepción: 8 de febrero del 2019

Fecha de aprobación: 26 de junio del 2019

Disponible en línea: 1 de julio del 2019

\section{Sugerencia de citación:}

Torres, J.(2019). Declive del liderazgo de EE. UU. con Trump y ascenso de China como opción del multilateralismo global. Razón Crítica, 7, 139-175, doi: 10.21789/25007807.1507

(a) Economista de la Universidad Nacional de Colombia, Magíster en Desarrollo Nacional y Planeación de Proyectos, Universidad de Bradford y Ph. D. en Ciencias Políticas, Universidad Libre de Berlín

Profesor de la Facultad de Ciencias Económicas y Administrativas de la Universidad de Bogotá Jorge Tadeo Lozano, Colombia

jaime.torresg@utadeo.edu.co

https://orcid.org/0000-0002-0340-8613 


\section{R E S U M E N}

En este escrito se analiza cómo el liderazgo global resultante de los acuerdos de Bretton Woods ha sufrido un proceso de desgaste, lo que se muestra con la crisis financiera del 2008 y la fragilización de las economías de EE. UU., Japón y la Unión Europea, en la cual se disminuye su participación en la economía mundial. Adicionalmente, el presidente Donald Trump propicia la desintegración del multilateralismo y, por tanto, mina el propio liderazgo que su país ejerció desde la Segunda Guerra Mundial. Las instituciones financieras multilaterales creadas en Bretton Woods se muestran poco flexibles para dinamizar la economía de los países en desarrollo debido a sus limitaciones en la estructura de capital y a la escasez de recursos. En este contexto, las regiones más dinámicas del globo, China y países del Asia, pueden hacer uso de sus grandes excedentes financieros y tecnológicos acumulados durante las últimas décadas, para jalonar con mayor vigor tanto la economía como la institucionalidad global. La iniciativa china para la construcción de una Nueva Ruta de la Seda está ofreciendo al mundo con un liderazgo diferente, centrado en la construcción de infraestructura y la unión de voluntades para hacer realidad multitud de proyectos, en la la mayoría en países en desarrollo, lo que hace que, junto con Europa y otras regiones, se abran espacios políticos para ampliar el multilateralismo, y se llene el vacío que están dejando los EE. UU.

PALABRAS CLAVE: Instituciones, Bretton Woods, Donald Trump, FMI, Banco Mundial, EE. UU., China, Ruta de la Seda, India. 


\section{A B S T R A C T}

This paper studies how global leadership resulting from the Bretton Woods agreements has suffered a decay process, as demonstrated by 2008 financial crisis and the fragility of US, Japan and UE economies, whose importance for world economy has weakened. Meanwhile, President D. Trump fosters the breakdown of multilateralism and, therefore, undermines the global leadership that his country has exercised since World War II. Besides, multilateral financial institutions created in Bretton Woods are not flexible enough to stimulate the economy of developing countries due to their limitations in terms of capital structure and the scarcity of resources. In this context, the most dynamic regions of the globe, China and the Asian countries, could make use of their large financial and technological surpluses, accumulated during the last decades, to boost with greater strength both global economy and institutionalism. The Chinese initiative for the construction of a "New Silk Road" is offering the world a different leadership approach -focused on the construction of infrastructure and the unification of acts of willingness to make multiple projects come true, mostly in developing countries- that enables new political spaces to expand multilateralism and fill-up the gaps left by the US.

KEYWORDS: Institutions, Bretton Woods, Donald Trump, IMF, World Bank, USA, China, Silk Road, India.

\section{R E S U M O}

Analisa-se neste escrito como a liderança global resultante dos acordos de Bretton Woods tem sofrido um processo de desgaste. Se evidencia, deste modo, as consequências da crise financeira de 2008, e o enfraquecimento das economias dos EUA, Japão e a União Europeia, ao se diminuir sua participação na economia mundial. Além disso, o presidente D. Trump propícia a desintegração do multilateralismo e, por tanto, enfraquece a própria liderança que o seu país exerceu desde a Segunda Guerra Mundial. As instituições financeiras multilaterais criadas em Bretton Woods mostram-se pouco flexíveis para dinamizar a economia dos países em desenvolvimento, por causa de suas limitações na estrutura de capital e a escassez de recursos. Neste contexto, as regiões mais dinâmicas do globo, China e países asiáticos, podem fazer uso de seus grandes excedentes financeiros e tecnológicos acumulados durante as últimas décadas, para impulsar com maior vigor tanto a economia quanto a institucionalidade global. A iniciativa chinesa para a construção de uma "Nova Rota da Seda" está oferecendo ao mundo uma liderança diferente, centrada na construção de infraestrutura e a união de vontades para fazer realidade múltiplos projetos, na maioria em países em desenvolvimento. Isto faz possível que, junto com Europa e outras regiões, se abram espaços políticos para ampliar o multilateralismo, preenchendo assim o vácuo que está deixando os EUA. 


\section{N T R O D U C C I Ó N}

La crisis financiera mundial del 2008 ha desnudado los problemas de la arquitectura financiera y de la institucional global emanada de los acuerdos de Bretton Woods en 1944. Este acuerdo, liderado por EE. UU. y Europa occidental al final de la Segunda Guerra Mundial, ha estado dotado de instituciones financieras globales como el Fondo Monetario Internacional (FMI), el Banco Mundial (BM), la Organización Mundial del Comercio, así como instituciones políticas como la Organización de Naciones Unidas (ONU). Se supone que el esquema de gobernanza ${ }^{1}$ de las instituciones financieras definidas en Bretton Woods mantuvo un talante multilateral, con dominancia y condicionamientos de EE. UU. y Europa occidental como requisitos para financiar otras naciones del globo (Acharya, 2017; Kramer, 2012). El entramado financiero mundial posterior a la Segunda Guerra Mundial logró en sus inicios reactivar las economías de Europa occidental y Japón, lo que creó igualmente diferentes instituciones de banca multilateral regional ${ }^{2}$ a partir de los años 1950 (Thakur, 2017; Voutsa y Borovas, 2015; BMF, 2004), pero la grave crisis del 2008 mostró —nuevamente- que este padece grandes limitaciones.

Autores como Gómez-Jiménez (2010), refiriéndose a las tendencias de largos ciclos de la economía mundial, argumentan que la crisis del 2008

1 Por gobernanza se entenderá la aplicación de un sistema de acuerdos e instituciones basados en idearios políticos y económicos liberales liderados por gobiernos y élites del mundo occidental, para dirimir en foros plurales y bajo su tutela, las principales contradicciones entre naciones y la aplicación de estrategias políticas de alcance mundial.

2 Como el Banco Interamericano de Desarrollo, el Banco Asiático de Desarrollo, el Banco Áfricano de Desarrollo, entre otros. 
fue un punto neurálgico que inició su incubación desde 1973, cuando terminó el ciclo de gran crecimiento de la economía "real" (industrial) de la posguerra, produciéndose el abandono del patrón oro por parte de EE. UU., transición en la que el liderazgo del capital industrial fue asumido por el gran capital financiero, que se apoya en la especulación como palanca para producir ganancias, lo que generó en el 2008 la crisis de los bonos inmobiliarios en EE. UU. Esta crisis rápidamente se expandió a Europa y otras economías del globo que estaban muy vinculadas a la circulación de activos financieros altamente especulativos.

Actualmente, la arquitectura institucional definida en Bretton Woods afronta otro reto que no deja de ser paradójico: el principal modelador, mentor y líder de dicho tipo de gobernanza —EE. UU., a través de su presidente- la cuestiona severamente con múltiples declaraciones y acciones $^{3}$. El presidente Trump critica la orientación y políticas globales que su país lideró durante siete décadas, minando una visión multilateral de gobernanza que, así sea limitada, pueda ser acogida por otras naciones, recurriendo en cambio al unilateralismo para reestructurar las relaciones de su país con sus más importantes socios y antagonistas comerciales y políticos (Van Ham, 2018). Al mismo tiempo, la gran dinámica productiva y comercial del continente asiático y en especial de la República Popular China en el siglo xxi, países que se apoyan fundamentalmente en la economía real, plantea la emergencia de nuevos equilibrios políticos y financieros que obligan a replantear los esquemas de gobernanza y financiación del desarrollo en el concierto internacional. Se plantea entonces la siguiente hipótesis:

El tamaño y orientación de la institucionalidad financiera multilateral vigente es insuficiente para financiar nuevos grandes proyectos y requiere una mayor participación de las naciones emergentes para gestar nuevas instituciones que transformen y amplíen la gobernanza financiera global.

3 Tales como el retiro de EE. UU. del Tratado Comercial Transpacífico, negociado por la administración Obama; el congelamiento de negociación del tratado comercial con Europa; la renegociación del TLCan con México y Canadá; el retiro del acuerdo de París del 2015 sobre cambio climático; la denuncia del acuerdo para control nuclear con Irán y el retiro de varias organizaciones adscritas a las Naciones Unidas (Unesco y el Consejo de Derechos Humanos), entre otras decisiones. 


\section{Estructura del trabajo}

Para abordar la temática se ha estructurado este trabajo en las siguientes secciones: 1) se describe el cambio de la participación en la producción mundial de Asia, Europa y EE. UU. durante los dos últimos siglos.

2) Con base en estadísticas de la onU se analiza el déficit comercial de EE. UU. a partir de los años 1980, su relación con el direccionamiento de las inversiones externas de sus empresas y algunas implicaciones sobre el tipo de globalización industrial. 3) Se analiza la influencia de tradiciones políticas de los EE. UU. en el ideario del presidente Trump, que apoyan su visión crítica de la globalización vigente y su recurrencia al unilateralismo.

4) Se sopesan las asimetrías de los poderes de voto de las principales instituciones financieras emanadas de Bretton Woods, la emergencia de la financiación externa de China, y el surgimiento de nuevas instituciones de banca multilateral y de macroproyectos como la "Nueva Ruta de la Seda”, que empiezan a mostrar grandes potencialidades para la inclusión y el crecimiento sustentable de los países en desarrollo. 5) Finalmente, se concluye sobre la necesidad y conveniencia de reforma de la arquitectura financiera global, en la potencialidad de que evolucione hacia un sistema más inclusivo, multilateral y apoyado en inversiones "reales", que pueda llenar los vacíos que deja el declive del liderazgo de EE. UU. y la predominancia del capital financiero global.

\section{Transformación de la producción internacional en siglos recientes}

Existe una correlación directa entre la capacidad productiva de un país y su poder político (Gómez-Jiménez, 2010). Antes de la gradual expansión europea y su dominancia en el mundo, China e India eran los epicentros de mayor población, cultura, tecnología y producción económica. De acuerdo con la descripción de Buchner (2008, p. 3):

En el siglo xvini Europa logró finalmente conectarse con China e India, regiones que debido a su numerosa población, grados de urbanización, avances técnicos, así como a sus complejos mercados, hacían del Asia el área más dinámica del mundo preindustrial. Europa era en comparación, una región periférica que hacia el principio de la nueva era (capitalista), se desarrolló como otro actor en el sistema comercial asiático. 
Una cuantificación económica de esta situación se muestra en la figura 1, en la cual se aprecia que hacia 1800, China e India concentraban más de dos tercios de la producción manufacturera global (Marsh, 2012, p. 235), mientras que las regiones hoy más desarrolladas (Europa y EE. UU.) solo se acercaban a un tercio. Cien años más tarde esta distribución cambió radicalmente, y Asia participó solo marginalmente ${ }^{4}$. A finales del siglo xx y principios del xxi China e India recobran nuevamente una mayor y creciente participación. La tendencia sigue siendo a lograr un equilibrio en próximos años.

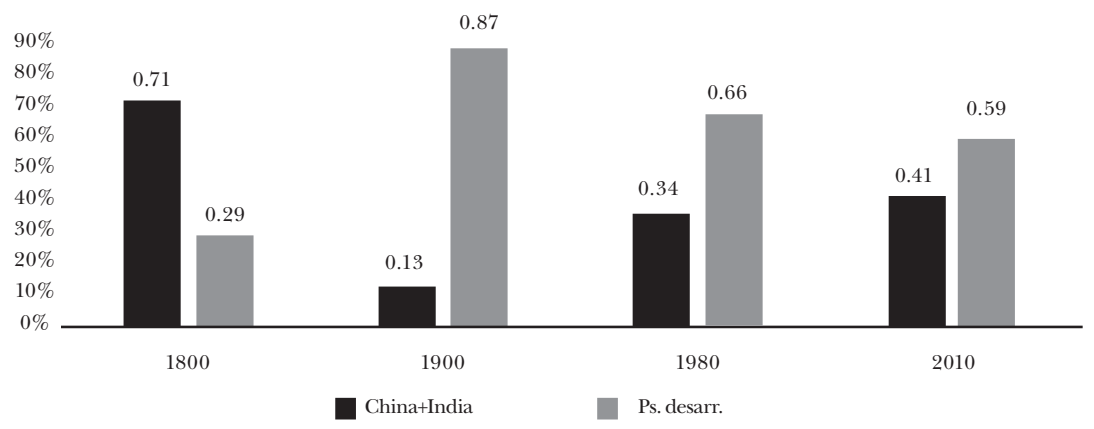

Figura 1. Participación \% en la producción manufacturera mundial. Fuente: Adaptado de Marsh (2012).

La revolución industrial que tomó inercia propia en Europa en los siglos XVIII y xix había acelerado a niveles nunca antes vistos la producción fabril, lo que permitió crear amplios mercados internos en Inglaterra, otros países de Europa y Norteamérica. También posibilitó la expansión global del comercio de artículos industriales, que, gracias al desarrollo de medios de transporte a motor como buques y trenes, hicieron posible la profunda visión de internacionalización de las élites de las principales naciones europeas, lo que completó en el ámbito internacional los procesos de globalización que anteriores civilizaciones (Egipto, China, Roma, Imperio Incaico...) habían iniciado regionalmente, pero que nunca llevaron hasta involucrar todos los rincones del planeta.

4 El poderío económico de China fue importante en el ámbito global hasta principios del siglo XIx, pero debido a graves conflictos internos que debilitaron su pujanza, tales como la sangrienta rebelión Taiping (1851-1864) contra el gobierno de la dinastía Qing, que había anexado nuevos territorios al imperio (Tibet, Taiwán y Mongolia). Estos conflictos, más las presiones e invasión de potencias europeas, de EE. UU. y Japón, fueron minando efectivamente sus capacidades. 
El balance de poder se inclinó decisivamente hacia Europa occidental con el correr del siglo xIx, a finales del cual se les unieron EE. UU. y Japón, mientras que la otrora pujanza asiática se redujo a niveles mínimos tras la colonización de India por Inglaterra, sumada a los conflictos internos y el desmembramiento de China por las naciones occidentales y Japón, a partir de 1895 con la primera guerra sinojaponesa. Los países de América Latina, por su parte, a pesar de la descolonización en el siglo Xıx, no lograron encontrar identidades nacionales que les abriera rutas de mayor cohesión social, democrática y de crecimiento económico (Palma, 2005; Shafaeddin, 2005). Tampoco los pueblos de África y gran parte del Asia pudieron librarse del statu quo colonial, sino hasta poco después de la Segunda Guerra Mundial, ocupando una posición desventajosa en el proceso globalizador durante buena parte del siglo xx (Amín, 1994).

Al iniciar la segunda mitad del siglo xx los dos países más poblados del planeta, China e India, inauguraron un largo proceso para recuperar sus identidades y soberanías nacionales, y aunque siguieron modelos diferentes, pero en ambos casos con gran intervención estatal, sentaron las bases para darle vigor a sus culturas y economías, reincorporándose con fuerza al comercio e institucionalidad globales, en parte aprovechando las libertades políticas y comerciales consagradas en los acuerdos de Bretton Woods (Acharya, 2017; Van Ham, 2018). De haber sido los mayores centros políticos y económicos durante muchos siglos, les tocó a estas populosas naciones recomenzar desde muy abajo en los años 1950, con altísimos índices de pobreza y analfabetismo, escasa infraestructura y múltiples carencias, para reconstituir sus sociedades, culturas y fortalezas económicas. A principios del siglo Xxi estos dos países muestran una gran recuperación, presentan altas y estables tasas de crecimiento económico, y sus poblaciones ganan rápidamente educación, calidad de vida e ingresos (Dhandapani, 2006; Mahtaney, 2007).

1950

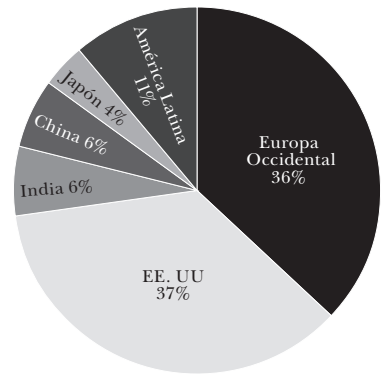

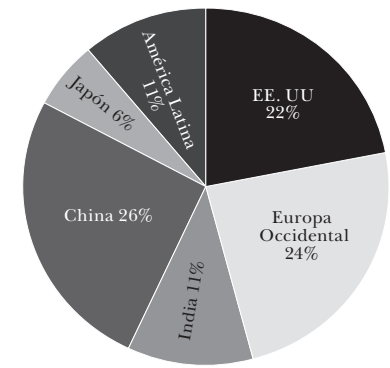

Figura 2. PIB mundial durante 1950 (a) y el 2017 (b).

Fuentes: cálculos propios a partir de Maddison (2006) para 1950 y el Banco Mundial (2017). 
Como se observa en la figura 2a, recién lograda su independencia hacia 1950, China e India sumadas apenas producían tanto como América Latina. En cambio, sus aportes a la producción global actualmente (2b) son considerables y están en expansión; China se convirtió en la mayor economía del planeta (PIB medido en precios de poder adquisitivo paritario-Banco Mundial). Además de sus milenarias y ricas culturas, en estas dos naciones se han ubicado todas las empresas transnacionales más importantes de la actualidad, generando desde allí modernas tecnologías, procesos que muchas empresas locales - tanto estatales como privadasestán absorbiendo y les permiten innovar por sí mismas, aportando bienes y servicios tecnológicos que se diseminan por todo el planeta. Teniendo en cuenta que la población de estos dos países sumaban 2.680 millones de personas a mediados del 2018 (www.cia.gov), las cuales son crecientemente involucradas por sus sistemas de gobierno como ciudadanías actuantes, más educadas y calificadas, constituirá un hecho singular del siglo xxi la gran irrupción de estas naciones en el concierto mundial, factor que ya está exigiendo la apertura de nuevos espacios en las estructuras financieras y de gobernanza global que empiezan a surgir en la presente coyuntura, de manera paralela al relativo declive del líder hegemónico del siglo xx. En el presente texto el análisis se concentrará en el ascenso de China, debido a que la emergencia de India se está produciendo con un poco de retraso respecto de la primera, y su impacto comercial y tecnológico está apenas tomando momento. Sin embargo, no cabe duda que, debido a sus rápidas tasas de crecimiento económico, en pocas décadas India ocupará lugares preeminentes en el mundo.

\section{Déficit comercial real e inversiones transnacionales de EE. UU.}

El crecimiento de la riqueza de una nación en el largo plazo se produce en buena parte por su capacidad para generar una balanza comercial positiva, es decir, por exportar establemente más bienes y servicios de los que importa, superávit que permite acumular recursos productivos, tecnológicos y financieros. Uno de los argumentos más poderosos que el presidente Trump ha esgrimido contra el tipo de globalización vigente es que su país mantiene un crónico déficit comercial con todas las naciones más productivas del planeta, lo que habría originado desempleo, éxodo de empresas, bajos ingresos y pérdida de poder político e industrial en EE. UU. En la figura 3 se presenta la balanza comercial de EE. UU. por exportación e importación de bienes y servicios: de ser ampliamente superavitaria a partir de la Segunda Guerra Mundial, se tornó deficitaria 
en los años 1970, perdiendo paulatinamente y hasta nuestros días su capacidad para exportar más productos de los que importa.

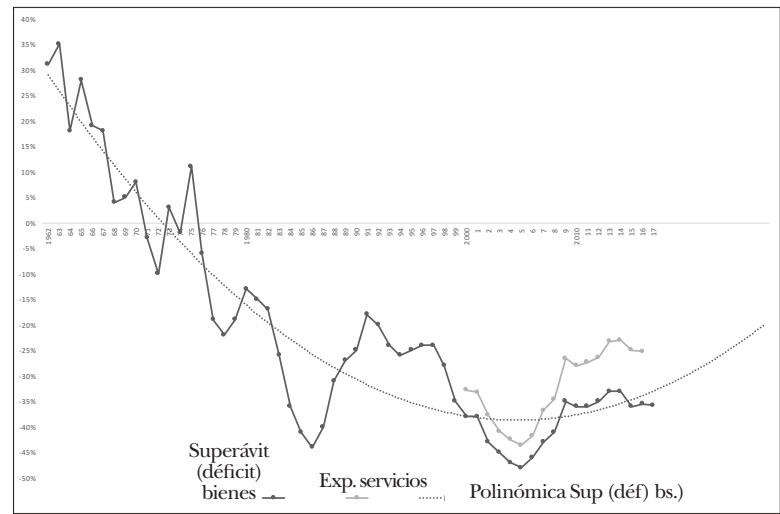

Figura 3. Superávit (déficit) comercial de bienes y servicios en EE. UU. 19622017/2027 (\% del valor importado de bienes y exportación neta de servicios, extrapolación a 10 años).

Fuente: elaboración propia con base en datos Comtrade. Función polinómica para extrapolación.

Cabe advertir que, al adicionar la balanza comercial de servicios (exportación neta de servicios en la figura $3^{[5]}$ ), se reduce el desbalance comercial de EE. UU. a poco más de la mitad. El presidente Trump nunca declara que la balanza de servicios de su país es positiva, omitiendo expresar que EE. UU. es líder en la prestación de servicios financieros internacionales: servicios técnicos, financieros, turismo y servicios educativos, entre otros. Técnicamente deben considerarse ambas partidas cuando se analiza el balance o desbalance comercial de un país, para no incurrir en opiniones sesgadas. Además, para ser precisos debería ampliarse el análisis del déficit al concepto de balanza en cuenta corriente, el cual además de la exportación neta de bienes y servicios, involucra el pago neto a factores de producción, cuya principal partida es la repatriación de utilidades de las empresas transnacionales que actúan globalmente. Una vez consideradas estas tres grandes partidas (bienes, servicios y repatriación de ganancias), se puede establecer técnicamente si un país se encuentra en situación estable o crítica de desbalance en sus relaciones comerciales y financieras con el mundo.

5 Los datos de Comtrade sobre la balanza de servicios solo empezaron a publicarse desde el 2000 . 
Para el caso de los EE. UU., la repatriación de utilidades fue ampliamente positiva y promedió entre USD 150 y 200 millardos cada año durante los últimos periodos (FED, 2018), indicando que, si esta suma se considera, el déficit en cuenta corriente del país se acerca a cero, es decir, las operaciones comerciales y financieras de EE. UU. con todo el mundo están prácticamente balanceadas. Estas cifras son diferentes a las parciales que usa con vehemencia el presidente Trump para denunciar "la injusticia" con que otros países tratan a su nación. Además, con la reforma fiscal que fue aprobada en diciembre del 2017, se aplicó una amnistía para las empresas de EE. UU. con utilidades retenidas en el exterior, que solo durante el primer semestre del 2018 significó una repatriación de USD 300 millardos (FED, 2018):

Investigamos cómo las compañías con grandes tenencias de efectivo en el extranjero han utilizado esos fondos siguiendo la "Ley de Recortes de Impuestos y Empleos” [...], que eliminó los desincentivos fiscales anteriores en la repatriación de ganancias extranjeras. Antes de la Ley de Recortes de Impuestos y Empleos las ganancias extranjeras de las empresas multinacionales de los Estados Unidos (EMN) estaban sujetas a impuestos de los EE. UU., pero solo cuando eran repatriadas. Este sistema incentivó a las empresas a mantener sus ganancias en el extranjero y, para fines del 2017, las EMN de los EE. UU. habían acumulado aproximadamente \$ 1 billón en efectivo en el exterior, en su mayoría en valores de renta fija de los EE. UU. Según la TcJa, los EE. UU. pasaron a un sistema impositivo cuasiterritorial en el que las ganancias se gravan solo cuando se obtienen (sujetas a impuestos mínimos); a partir de ahora, las ganancias extranjeras de las empresas multinacionales estadounidenses ya no estarán sujetas a los impuestos de los EE. UU. cuando sean repatriadas. Como transición a este nuevo sistema impositivo, la TCJA impuso un impuesto único (pagadero durante ocho años) sobre el stock existente de tenencias en el extranjero, independientemente de si los fondos se repatriaron, eliminando así el incentivo fiscal para mantener efectivo en el extranjero. Los datos de la balanza de pagos muestran que las empresas estadounidenses repatriaron poco más de $\$ 300$ mil millones en el 2018: primer trimestre, aproximadamente el 30\% de las existencias estimadas de tenencias de efectivo en el extranjero. Como referencia, las amnistías fiscales del 2004, que proporcionaron una reducción temporal de un año en la tasa impositiva de repatriación, resultaron en \$ 312 mil 
millones repatriados en el 2005 , de un estimado de $\$ 750$ mil millones mantenidos en el extranjero. Cabe señalar que la repatriación refleja la transferencia de fondos a los EE. UU. en términos puramente contables: los fondos previamente mantenidos por una filial extranjera ahora están en manos de la matriz estadounidense.

A pesar de las enormes cifras por repatriación de utilidades, no deja de ser preocupante que un país presente un déficit crónico en su comercio exterior de productos, pero también debería esperarse que su más alto dignatario presentara con claridad las cifras macroeconómicas, para no incurrir en imprecisiones, o lo que muchos analistas catalogan como lenguaje "populista" del presidente Trump, destinado a lograr efectos emocionales en su electorado a través de la manipulación de cifras (Higgott, 2017). Si analizamos solo el déficit comercial en bienes de este país (el argumento del presidente), podemos concluir que se ha vuelto estructural, que es permanente desde hace 40 años, y se genera porque en casi todas sus industrias manufactureras (excepto la aeronáutica y recientemente petroquímica) los EE. UU. acumulan déficits con los países más competitivos del globo, tal como se aprecia en figura 4.

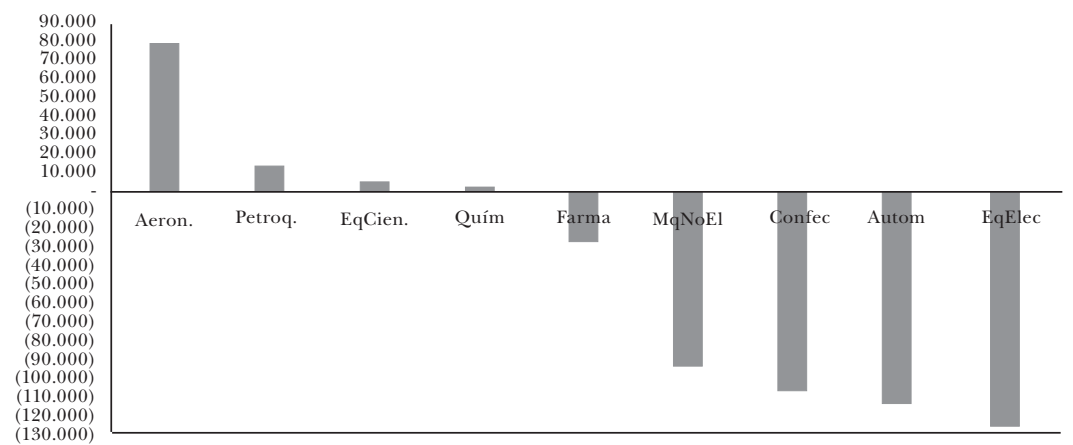

Figura 4. Balanza de las industrias de EE. UU. Con el mundo. Promedio 2010/2015 (millones de USD).

Fuente: Cálculos propios a partir de datos de Comtrade-onu.

En sectores industriales tan importantes como equipos electrónicos, maquinaria eléctrica y no eléctrica, automotores y farmacéutica, los EE. UU. presentan un comercio deficitario con países como China, Japón y Corea, así como con los más importantes de Europa y también con sus socios del Tratado de Norteamérica: Canadá y México. Lo paradójico es 
que parte importante de la producción exportada por estos países a EE. UU. proviene de empresas filiales de matrices estadounidenses (como Apple, General Motors, Caterpillar, General Electric, Abbott, entre muchas otras), que abrieron sucursales en esas naciones al encontrar tejidos sociales y productivos que les ofrecieron condiciones ventajosas y mayores ganancias en comparación a si produjeran desde su país de origen. Este es uno de los resultados del tipo de globalización liberal que ha sido posible por los acuerdos de Bretton Woods (liberalización de flujos de inversiones y capitales).

Una de las características más salientes del tipo de globalización vigente es que las poderosas empresas transnacionales pueden migrar a todos los destinos donde encuentren favorables condiciones productivas: su vecindad (Canadá y México), Europa o, en las últimas décadas, Asia, donde se presentan los mayores y más dinámicos crecimientos económicos del planeta. Las empresas estadounidenses son las que han comandado y más se han beneficiado de esta migración ${ }^{6}$, lo que provoca menos puestos de trabajo en su país - especialmente trabajos industriales-, pero comprando abundantes productos y servicios industriales desde su país y otras regiones del globo, bienes que posteriormente son vendidos en todo el planeta - especialmente en los EE. UU.- . De acuerdo con datos de Portafolio ("Ventas de empresas de EE. UU. a China", 2018), el valor de los productos fabricados y vendidos en otro mercado de gran crecimiento, China, por empresas filiales de casas matrices estadounidenses en ese país, ascendió a la enorme suma de USD 222 millardos en el 2015:

En el 2015, las subsidiarias multinacionales estadounidenses con sede en China obtuvieron un total de USD 221.900 millones en ventas a consumidores nacionales (de China). Los bienes y servicios vendidos fueron producidos por un ejército de 1,7 millones de personas empleadas por subsidiarias estadounidenses en el país. Por el contrario, la presencia corporativa de China en EE. UU. sigue siendo pequeña. Las cifras oficiales de las ventas de las filiales de las empresas chinas a los consumidores estadounidenses no existen, pero los analistas estiman que son insignificantes en comparación con las exportaciones de China a EE. UU. Por lo tanto, la "relación económica agregada” entre EE.UU.

$6 \quad$ Expresado en el hecho de que ocupan los primeros puestos en casi todas las grandes industrias del planeta, según se aprecia en los diferentes rankings globales por sus valores en bolsa y ventas consolidadas. 
y China parece ser mucha más equilibrada de lo que aparenta según el déficit comercial.

Las empresas transnacionales de todos los países saben que participar del mercado interno de naciones tan grandes y de rápido crecimiento como China (también India) se vuelve una política imprescindible para su presencia global (González-Sáez, 2018). Para ubicarse allí, requieren de grandes recursos financieros, tecnológicos e insumos. De esta manera, sus gigantescos procesos de outsourcing ${ }^{7}$ son dirigidos a minimizar los costos finales de producción a través de la eficiente participación en cadenas globales de valor (PIIE, 2018), sin que esa producción a escala global implique una "lealtad" de las empresas con el Estado de origen: las decisiones empresariales se toman considerando la optimización mundial de sus ganancias, no la generación de empleo y pago de impuestos en sus países sede. Este es el tipo de globalización que ha emanado tras varias décadas de los acuerdos de Bretton Woods, especialmente practicado por las firmas estadounidenses, y el cual es duramente criticado por el presidente Trump.

Adicionalmente, es importante considerar las transformaciones que aparecen paulatinamente en el equilibrio global cuando se confirma que países como China no abren sus grandes mercados locales a las empresas transnacionales sin contraprestaciones: exigen que las empresas extranjeras se asocien con empresas locales, muchas de ellas pertenecientes al Estado y, adicionalmente que transfieran parte de sus conocimientos industriales a los locales (Torres-González, 2016). Cuando este tipo de estrategias productivas se desarrollan durante décadas, los países y las empresas locales van ganando capacidades tecnológicas y convirtiéndose en grandes competidoras de las empresas extranjeras. En el largo plazo, los liderazgos industriales y tecnológicos se van redistribuyendo entre diferentes naciones del globo, participando cada vez con mayor fuerza países que - como China e India- cuentan con claras políticas industriales y tecnológicas para el desarrollo de sus economías. No es en vano que la pérdida del superávit comercial de tantas industrias que exportan desde los EE. UU. (figura 4) va produciéndose, en parte en beneficio de la producción de sus propias filiales en China, las cuales necesariamente deben compartir conocimientos y tejidos productivos con

7 Se refiere a la compra masiva de insumos y servicios industriales del extranjero, los cuales antes se producían internamente. 
empresas cuyas casas matrices están radicadas en los países de sus nuevos socios industriales.

En este punto del análisis es conveniente preguntarse si los beneficios económicos y políticos del comercio internacional deben contabilizarse desde el ángulo nacional (para un país como EE. UU.) o si deberían estimarse de manera consolidada (global), incluyendo las operaciones de las empresas transnacionales de una nación, independientemente de los numerosos países en que se localicen: la globalización liberal propiciada desde los acuerdos de Bretton Woods en 1944 choca contra los intereses puramente "nacionales", tales como los reclamados por el presidente Trump.

\section{Tradiciones políticas que apoyan al presidente Trump y la "reversa globalizadora"}

La forma como el presidente Trump reclama es considerada por muchos analistas como "impredecible". El carácter "transaccional" que imprime a sus negociaciones, su constante apelación crítica al tipo de globalización heredada de Bretton Woods, muestran a este presidente como un continuador de tradiciones nacionalistas existentes desde la constitución de la nación norteamericana. Según Alexander Hamilton, primer secretario del tesoro de los EE. UU. independientes (17851789), quien planteó el marco de una economía política para que el país se industrializara y propugnaba un gobierno fuerte, proteccionista y opositor del libre comercio - impulsado entonces por Gran Bretaña-, debía el Gobierno tener como objetivo construir una nación que se apoyara preferentemente en los recursos internos del naciente Estado (Magness, 2018). El cambio de énfasis del presidente Trump en las relaciones internacionales hacia una agenda más local y proteccionista rememora los retos de los primeros días del hamiltonianismo, cuando los intereses locales/regionales tendieron a prevalecer, precisamente por el reconocimiento de que se trataba de una nación en desarrollo, recién independizada y con numerosas necesidades internas.

8 En su lenguaje, "hacer negocios" (deals) de manera bilateral con sus principales contrapartes, cuyo cálculo parece dirigirse a lograr una ganancia para su país (y empresas), aparentemente sin considerar aspectos estratégicos o globales, que en el sistema de Bretton Woods usualmente se negociaron multilateralmente con sus mayores socios. 
A mediados del siglo xx los EE. UU. ya se habían colocado en posición de liderar un orden mundial más multilateral, con el apoyo de sus socios europeos y, ahora sí, con apego al libre comercio (Bolt, 2015). Acogiendo tradiciones ideológicas de su país, el presidente Trump parece regresar a principios nacionalistas como el proteccionismo arancelario ${ }^{9}$, utilizado intensamente en fases primarias del desarrollo económico de EE. UU. - y de todos los países del orbe (Chang, 2003)—, pero superado por los sucesores políticos de Hamilton en la medida que hoy es una nación líder en tecnología, considerando la mayoría de analistas como más eficaz y productiva la competencia con ella que con proteccionismo arancelario (Stiglitz, 2018).

Otros analistas (Jones y Khoo, 2017; Hamilton, 2017) ubican el ideario de Trump y sus seguidores en la tradición jacksoniana, haciendo referencia a la herencia del séptimo presidente de la Unión, Andrew Jackson (18291837), quien centró su gobierno e ideas en temas locales, más que en iniciativas de política exterior. De manera similar al discurso de Trump, defendió los derechos del "hombre común”, propició el proteccionismo arancelario y auspició la ampliación del voto universal de los hombres blancos. La defensa por Jackson de los derechos populares en el siglo xIX tiene semejanza a la planteada por Trump, en el sentido que Trump busca "devolver los trabajos y las industrias a EE. UU.", "frenar la inmigración" y otras estrategias con las que fundamenta su cruzada proteccionista, nacionalista, y la tendencia antiglobalizante (Higgott, 2017).

Dentro de las principales decisiones económicas tomadas por la administración Trump — contra toda la filosofía aperturista de los tratados de libre comercio que anteriores gobiernos habían negociado-, destacan la renuncia a los más significativos tratados en proceso de implementación: el Transpacific Partnership, recién acordado por la administración Obama con Japón, Australia, México, Chile, Canadá y otros seis países (excluyendo significativamente a China), mientras también congeló las negociaciones en curso con la Unión Europea para el Transatlantic Trade and Investment Partnership, que sería uno de los mayores tratados de libre comercio vigentes en el globo.

A pesar de la importancia de estos dos tratados, que trazaban una ruta estratégica — comandada por EE. UU.—y que deberían

9 A través de la imposición de aranceles a la importación de hierro y acero, aluminio, panales solares, productos tecnológicos y una extensa lista adicional. Estos aranceles se dirigen principalmente contra China, pero también afectan a la Unión Europea, Brasil, México, Canadá, Corea, Colombia y numerosos países más. 
ser la referencia internacional obligada para las inversiones y el comercio del siglo xxi, el presidente Trump optó por desconocerlos y volcar su agenda de negociación económica, primero, hacia algo más cercano: el Tratado de Norteamérica (North American Free Trade AgreementNafta), en cuya renegociación con sus dos socios regionales, Canadá y México, aspira lograr éxitos económicos más inmediatos y más tangibles. En segundo término, decidió declarar una "guerra comercial" contra China, buscando a través del proteccionismo, mantener la superioridad tecnológica de su país. La voluntad política del presidente Trump y su equipo muestra estar mucho más interesada en protegerse comercialmente y organizar los asuntos internos de su país, que en mantener un liderazgo internacional basado en la promoción de libertades e innovación tecnológica (Van Ham, 2018), en la medida que considera que la fortaleza interna es la que confiere fortaleza externa, y no al revés. Paradójicamente, la defensa política de las virtudes del libre comercio están quedando en manos de China.

El presidente Trump cuenta entonces con suficientes argumentos anclados en tradiciones políticas de su país, para plantear su trayectoria de gobierno. Sin embargo, cabe preguntarse si retrotraer el liderazgo global de EE. UU. a temas más locales y proteccionistas, aislándose progresivamente de compromisos previos de su país, significa el reconocimiento tácito del declive de su poder internacional y de su tradicional papel como poder hegemónico. En su discurso de posesión como presidente el 20 de enero del 2017, Trump se refirió a la economía, la distribución internacional de la riqueza, el declive industrial y laboral de su país de la siguiente manera:

Durante muchas décadas hemos enriquecido la industria extranjera a expensas de la industria estadounidense [...] y hemos gastado billones y billones de dólares en el extranjero, mientras que la infraestructura de Estados Unidos se ha deteriorado. Hemos hecho ricos a otros países, mientras que la riqueza, la fortaleza y la confianza de nuestro país se han disipado en el horizonte. Una por una, las fábricas cerraron y abandonaron nuestras costas, sin siquiera pensar en los millones y millones de trabajadores estadounidenses que quedaron atrás. La riqueza de nuestra clase media ha sido arrancada de sus hogares y luego redistribuida en todo el mundo. Pero eso es el pasado. Y ahora solo estamos mirando hacia el futuro ("The full text of Donald Trump's inauguration speech", 2017). 
La agenda de la administración Trump define una mayor prelación hacia los asuntos locales y hacia un manejo poco consultivo con el resto del mundo, que hacia la consolidación del liderazgo ejercido por gobiernos previos de su país, los cuales gestaron el orden mundial posterior a Bretton Woods. Sus múltiples decisiones políticas y económicas claramente indican que la administración Trump tiene metas nacionalistas que no consideran necesario ser fiel a los compromisos que anteriores administraciones de su país adquirieron para sustentar el orden global heredado. El presidente Trump estima que la hora de ruptura con ese orden ha llegado, lo que también podría significar el principio del fin del liderazgo hegemónico que hasta el presente los EE. UU. han tutelado.

Los estables déficits comercial y fiscal ${ }^{10}$ (twin-deficit) de EE. UU. demuestran falencias en las estructuras productiva y financiera al interior de esa economía. Otro importante factor que debilita el liderazgo hegemónico que este país ha ejercido hasta el presente consiste en que muchas de sus grandes empresas transnacionales continúan acumulando producción, ventas y ganancias en China y múltiples lugares del mundo, lo que muestra que su reubicación global y la fusión con otras economías ha sido conveniente para sus intereses como empresas transnacionales, a pesar de que al país matriz y a su gente no les vaya tan bien, o no tanto como a estas empresas que están entre las mayores beneficiarias del tipo de globalización a principios del siglo Xxi.

Tal como lo indican las cifras macroeconómicas globales, la geopolítica del planeta está cambiando aceleradamente en lo que va corrido del presente siglo, inclinándose hacia un mayor peso del Asia. Esta tendencia continuará y hará necesario reconocer que el poder y liderazgo de los EE. UU. realmente no cuentan con un respaldo tan amplio como

10 El déficit fiscal de los EE. UU. se disparó de USD 459 millardos en el 2008 a USD 1.413 millardos en el 2009, debido a la crisis financiera (9,8\% del PIB). A partir del 2013 bajó de nuevo de los USD mil millones, y se situó en usD 679 mil millones (4,1\% del PIB); en el 2014, en USD 485 mil millones (2,8\%); en el 2015, usD 438 millardos (2,4\%); en el 2016, en USD 585 mil millones (3,1\% del PIB); en el 2017, en USD 665 (3,4\%); en el 2018 un estimado de USD 779 (4,0\%), y en el 2019 un estimado de USD 1.091 millardos ("U.S. Budget Deficit by Year Compared to GDP, Debt Increase, and Events”, 2019). Los EE. UU. pueden financiar estos déficits en gran parte porque otros países le compran títulos de la Reserva Federal, siendo los porcentajes más representativos los siguientes: China, usD 3.095 millardos (3,1 billones); Japón, USD 1.293 millardos; la Unión Europea, USD 858 millardos; Suiza, usD 800 millardos; Arabia Saudita, USD 505 millardos; Rusia, usD 492 millardos; Taiwán, usD 465 millardos; Hong Kong (China), usD 436 millardos; India, usD 422 millardos; Corea del Sur, usD 404 millardos; Brasil, UsD 384 millardos. Se aprecia que las reservas del Banco Central de los EE. UU. se nutren en una proporción enorme de los depósitos de Asia del Este, especialmente de China y Hong Kong, Japón y Taiwán. Datos correspondientes a abril del 2019 ("List of countries by foreign-exchange reserves", s. f.). 
lo tuvieron en la segunda mitad del siglo xx o, en los 1990, cuando ayudaron a implosionar a la Unión Soviética. El real poder político y militar de EE. UU. se muestra sobreexigido, las cargas sobre sus espaldas parecen pesar más que los músculos que las sostienen. La práctica doctrina jacksoniana del presidente Trump sencillamente confirma esta nueva situación con implicaciones globales, y su retiro paulatino de diferentes esferas puede considerarse tanto previsible como una opción de recambio y rejuvenecimiento de la gobernanza mundial y, entre sus constituyentes, de la banca multilateral. El campo que están dejando los EE. UU. debe ser llenado con los aportes de las demás naciones, siendo China y, crecientemente, India estados clave para complementar los esfuerzos multilaterales de Europa, junto con otras naciones del globo (como del G20 $0^{[11]}$ ) y de múltiples organizaciones civiles y científicas, que cada día aportan más propuestas de soluciones y demandas por mejoramientos en la gobernanza y el apoyo económico (Acharya, 2017; Avant, Kahler, \& Pielemeier, 2017).

Algunos signos positivos que pueden favorecer esta apertura se presentan en casos como que ante la decisión de la administración Trump de retirarse del acuerdo climático firmado en París en el 2015, los jefes de gobierno de la Unión Euroepea, China, India y la totalidad de estados miembro de la ONU, así como múltiples organizaciones científicas y civiles, ratificaron su decisión de continuar con el acuerdo. Los 11 países signatarios del ahora rebautizado Comprehensive and Progressive Agreement for Transpacific Partnership (menos EE. UU.), igualmente decidieron continuar con el tratado que entró en vigor el 30 de diciembre del 2018. El acuerdo de desarrollo antinuclear con Irán fue ratificado por los demás signatarios, a pesar del retiro de EE. UU. La iniciativa de la Ruta de la Seda (de China) invita a crear espacios para un gigantesco plan global de inversiones en infraestructura y comercio. Estas acciones indican que el repliegue de EE. UU. como líder global en diferentes ámbitos abre el reto de que el liderazgo pueda ser reconstruido de manera más participativa, sustentable y productiva para el desarrollo de una sociedad global mejor integrada.

11 Grupo de los 20, que reunió con posterioridad a la crisis financiera del 2009 a las naciones más influyentes del globo, incluyendo las del G7: Rusia, China, India, Suráfrica, Australia, Corea del Sur, Brasil, México y Argentina. 


\section{Derechos de voto en las instituciones financieras de Bretton Woods y asimetría del poder global actual}

El liderazgo en las instituciones globales da la posibilidad de moldear los principales desarrollos políticos, económicos o ambientales de las naciones y el planeta. De esta manera, instituciones económicas emanadas de los acuerdos de Bretton Woods como el FMI han logrado presionar la adopción de su visión sobre regímenes cambiarios, ajustes macroeconómicos e importantes decisiones políticas en los países que asiste en momentos de crisis financieras. El вм influye decisivamente en qué tipo de inversiones y países financia —y cuáles no (вмz, 2004)—, y la oмС acuerda regímenes comerciales cada vez más liberalizados (anteriores a la era Trump), lo que ocasiona así que EE. UU., la Unión Europea y Japón dirijan y tutelen las más importantes políticas globales, gracias a su liderazgo y participaciones mayoritarias en dichas instituciones. Las instituciones que mayor presencia y recursos manejan son las de asuntos económicos, particularmente el FMI y el BM, en las cuales EE. UU. y la Unión Europea se reservan el nombramiento de sus directores, manteniendo una amplia dominancia sobre el resto de naciones a través de su mayor capacidad de voto, siendo no poco frecuente que sus decisiones tengan sesgos políticos ${ }^{12}$.

En un análisis de los Ministerios de Finanzas y Cooperación del gobierno Alemán (вмғ \& вмz, 2004, p. 6) se interpretan los errores de conducción de esas intituciones de la siguiente manera ${ }^{13}$ :

Dada la crisis de deuda externa de los años 1980 (sobre todo en Latinoamérica), así como las fuertes crisis financieras y cambiarias de los años 1990 en Asia, Latinoamérica y Rusia, debieron las instituciones (de Bretton Woods) cuestionarse las políticas usuales de prevención y superación de crisis, convirtiéndose en tarea prioritaria. El tamaño de las crisis y sus graves consecuencias - que no fueron previstas por medios oficiales ni por el sector privado-

\footnotetext{
12 Una reciente actuación políticamente sesgada del вм correspondió al reconocimiento por parte de su economista-jefe, Paul Romer, de haber manipulado información para el cálculo del Índice Global de Competitividad "Doing Business" en detrimento de Chile. Romer admitió que la institución había desmejorado artificialmente sus indicadores durante el segundo gobierno de la presidenta socialista Michelle Bachelet, lo que tuvo incidencia política negativa en los resultados electorales presidenciales del Partido Socialista ("El Banco Mundial reconoce que perjudicó a Chile alterando el índice de competitividad”, 2018).

13 Traducción del alemán por el autor.
} 
evidenciaron la necesidad de modificaciones en el sistema financiero internacional, así como de importantes reformas a las instituciones de Bretton Woods. En el campo de las políticas de desarrollo se hicieron notorios los déficits de los programas de ajuste estructural para la lucha contra la pobreza y el sobreendeudamiento de las naciones más pobres, exigiendo un cambio fundamental de su unilateral orientación. Debieron por tanto diferenciarse y complementarse las estandarizadas recomendaciones políticas neoliberales del consenso de Washington. También fue reconocido que un elevado condicionamiento de los créditos para naciones pobres puede conducirlas al sobreendeudamiento. El FMI y el Bм han aprendido de esas experiencias y adoptado reformas que colocan la autodeterminación (ownership) de sus propios procesos de desarrollo en el centro de la atención.

Con el propósito de establecer parámetros que indiquen la representatividad existente en las organizaciones económicas multilaterales, se calcula en la figura 5 la relación entre los tamaños de las poblaciones de los países, sus participaciones en la producción mundial (PIB en cifras poder de paridad adquisitiva- $\mathrm{PPA}^{14}-$ ) y sus derechos al voto en el FMI y el BM, tanto para EE. UU., UE, China e India, como para el resto del mundo entre el 2000 y el 2017.

Como se aprecia, China pasó de producir el $8 \%$ del PIB mundial en dólares-PPA en el 2000, para llegar a más del doble de esa participación en el 2017, ubicándose como la mayor economía del planeta gracias a su vertiginoso crecimiento, siendo también el país más poblado. India, el segundo más habitado, subió del 4 al 7\% del PIB en el mismo periodo, mientras que EE. UU. y la Unión Europea, que entre ambos suman el $11 \%$ de la población mundial, redujeron sus participaciones en cerca de una cuarta parte cada una. Es decir, los pesos relativos en la producción mundial están cambiando rápidamente, superando para China el tamaño de su población, mientras India, un poco más lentamente, también se acerca.

14 El "Producto Interno Bruto PPA" (medido como "Poder de Paridad Adquisitiva") de las naciones en desarrollo es usualmente mayor que el mismo medido en usD corrientes, debido a un ajuste que se les reconoce por presentar costos de vida menores que aquellos de las naciones desarrolladas. 

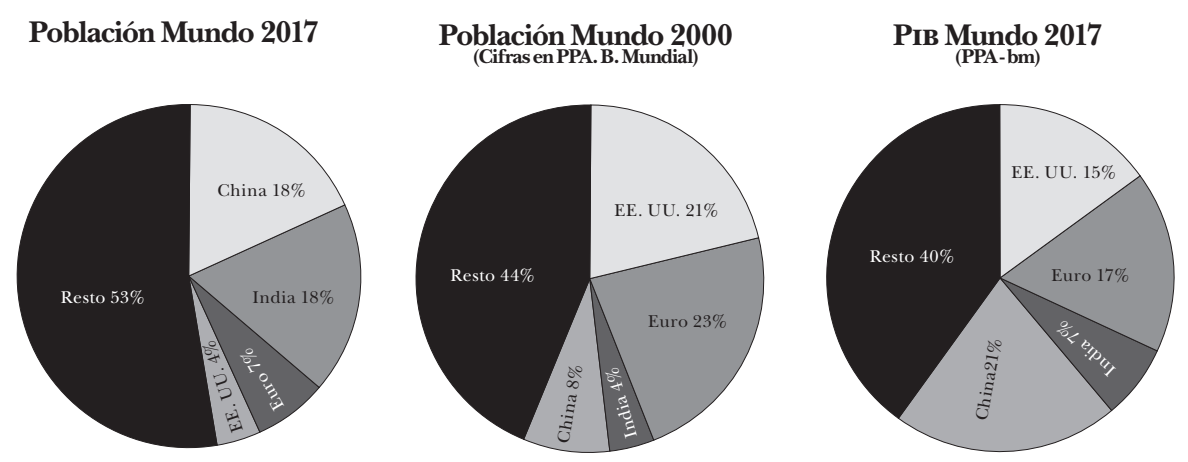

Figura 5. Población y Рів mundial en el 2000 y el 2017. Nota. Cifras del PIв en dólares PPA.

Fuente: Banco Mundial (2018).

Con el propósito de remediar los efectos de la última gran crisis financiera del 2008, y fruto de las reuniones del G20, se hizo necesario revisar en el 2010 los aportes financieros y derechos de voto en el FMI у вм, para reducir las amplias distancias que existían - y que aún subsisten- entre sus miembros. Es de observar que las participaciones en las instituciones de Bretton Woods de países tan importantes como China e India (figura 6) empezaron siendo mínimas y guardan muy baja simetría con sus capacidades económicas y niveles actuales de población.

Mientras China tiene el 18\% de la población y el 21\% de la producción global, apenas contaba en el вм con una modesta cuota en derechos de voto del 2,77\% del total antes de la crisis financiera del 2008 y el 2009. Dada la necesidad de aumentar el capital del Banco en el 2010, su cuota ascendió al 4,42\% ("El Banco Mundial aprueba dar más peso a los países emergentes y una ampliación de capital”, 2010). Como comparación, Alemania participaba en el Bм con el 4,17\% en el 2009 y bajó a 3,75\% con la reforma del 2010. Los EE. UU. poseían un 35,07\% cuando se creó el вм y en el 2017 bajaron al 16,3\% (World Bank, 2017), reducción considerable, pero que, debido a la modificación de los estatutos del Banco, se compensó con el reconocimiento de un derecho excepcional: su "derecho de veto" a cualquier decisión del Banco ("El liderazgo de Estados Unidos en el Banco Mundial", 2019).

Una situación similar de baja representatividad se presenta en el FMI (“IMF Members' Quotas and Voting Power, and ImF Board of Governors", 2017), en el cual China pasó del 3,8\% en el 2009 al 6,09\% en el 2016. Por 
su parte, India ascendió ligeramente en las cuotas del FMI del 2,3\% en el 2009 al 2,64\% en el 2016, mientras tiene el 17\% de la población mundial y aporta el $7 \%$ del PIB global ${ }^{15}$. Destaca la gran participación que tiene la Unión Europea de los 28 países (incluído el Reino Unido) en los derechos de voto del FMi $(30,26 \%)$, lo cual resulta en un poder 4,3 veces mayor que el que sería proporcional a sus habitantes (figura 6b). Mientras tanto, China tiene solo 0,3 veces dicho poder por habitante - a pesar de que su producto interno bruto PPA es similar al de la Unión Europea-. India apenas llega a 0,15 veces y el resto del mundo a 0,77 veces. EE. UU. y Japón mantienen una alta jerarquía en las decisiones de voto, superiores a 3,5 veces en esta escala, definida por la población.

Se puede concluir que los derechos de voto de los países en el FMI, a pesar de los incrementos acordados después de las reformas del 2010 al 2017, siguen estando determinados por factores de poder definidos a la fundación del Fondo en 1944, y mucho menos por el tamaño de las poblaciones o el reconocimiento de la potencia actual de sus economías. Es decir, predomina en estas instituciones la inercia del régimen político tal y como fue definido a mediados del siglo xx, el cual poco se ha reformado para atender a la emergencia político-económica y las necesidades de crecimiento de otras naciones.

\section{\% Derechos de voto en FMI en el 2017}

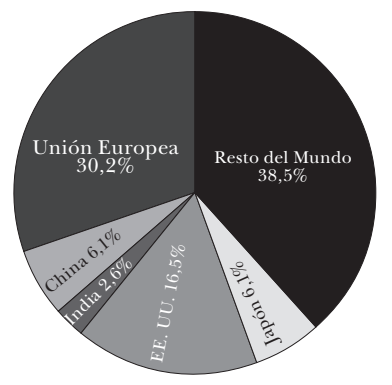

\section{Proporción derechos voto en FMI/población}

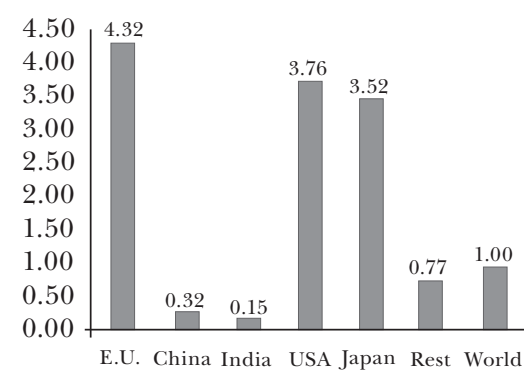

Figura 6. Derecho a voto frente a la población.

Fuente: FMI Informe Derechos de Voto 2017, cálculos propios (IMF, Voting powers, 2017)

La asimetría actual implica que Europa, Japón y EE. UU. mantienen cuotas de poder en el FMI por lo menos 10 veces mayores que las de China o 20 veces más altas que las de India, si la norma fuera democrática en el

15 http://www.thehindu.com/business/India-gets-more-voting-rights-in-IMF-reforms / article14024758.ece 
sentido de que todos los habitantes del planeta tuvieran igual derecho de voto en las decisiones del FMI. Lo anterior indica que todavía existe un largo camino por recorrer para que la globalización definida en Bretton Woods se acerque al ideal de igualdad que se proclamó en la Revolución Francesa en 1789. La gran diferencia a la hora de votar políticas y resoluciones implica que se puede aplicar una mayoría por EE. UU., Europa y Japón, así no se juzguen como suficientes o convenientes por el resto de naciones.

\section{Transformación de la estructura financiera global y la Nueva Ruta}

\section{de la Seda}

Dadas las mayores necesidades de financiamiento multilateral para las naciones en desarrollo ${ }^{16}$, así como la recurrencia de las crisis financieras regionales y globales, se hace necesario que la banca multilateral tenga mayores recursos, instrumentos y represente más equilibradamente a las diferentes naciones, que son sus accionistas minoritarios. Las actuales participaciones de los países en el capital de estas instituciones y las prácticas que estas últimas han seguido, de acuerdo con lo definido dentro de la arquitectura financiera de Bretton Woods, se presentan hoy como insuficientes para ofrecer políticas y recursos adecuados para las necesidades de desarrollo de la mayor parte de naciones del globo (Hutson \& Kearney, 2009), especialmente de aquellas que no han desarrollado suficientemente sus infraestructuras locales y regionales, ni los mercados financieros privados, es decir, los países en desarrollo.

En estas condiciones, la emergencia de China como poder comercial global y como país que cuenta con gigantescos superávits comerciales, acumulación de reservas internacionales y un sustancial volumen de ahorro interno, le están permitiendo estructurar una política crediticia internacional con capacidad para financiar grandes proyectos de desarrollo en muchas naciones, complementando las capacidades crediticias del Bм y la banca multilateral que gira a alrededor de este ${ }^{17}$,

16 Entre los grandes retos para financiar proyectos de desarrollo, el BAII considera en su informe del 2019: "Infrastructure finance is long term and particularly sensitive to the credit environment, especially in Asia where it remains predominantly driven by bank loans due to less-developed capital markets. For projects in the region that enter the market for financing, over 90 percent is currently raised from commercial bank loans, according to Moody's. Moreover, ADB estimates that the infrastructure financing gap in the region is around USD 459 billion per year".

17 Los bancos multilaterales regionales son el Banco Interamericano de Desarrollo (BID), el Banco Asiático de Desarrollo (BDASIA), el Banco Africano de Desarrollo (BDAfr), el Banco Centroamericano de Integración y Desarrollo (BCAмID), en los cuales EE. UU., Europa y Japón tienen inversión y poder de decisión significativas, que les permite alinear sus políticas con las del вм у еl ғмі. Otras siglas usadas en la figura 7 son: BIslam: Banco Islámico de Desarrollo; BAsInfra: 
así como captar recursos financieros en mercados privados y también con emisión de bonos de deuda denominados en yuanes. En la figura 7 se aprecian los volúmenes crediticios comprometidos a través de préstamos, tanto por bancos estatales chinos como por el resto de la banca multilateral que financia inversiones en países en desarrollo.

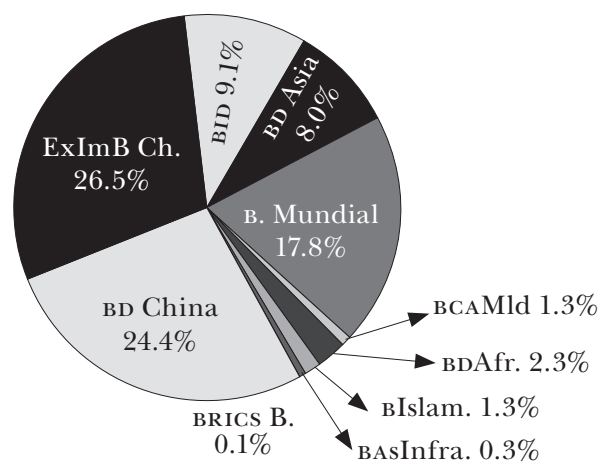

Figura 7. Saldo de préstamos a países en desarrollo durante el 2017 y el 2018.

Fuentes: informes anuales del 2018 de cada institución; FMI informe abril del 2018 e informe del 2017 para Banca China y BDAF.

Como se aprecia en la figura 7, para el 2017 y el 2018, los préstamos internacionales concedidos a países en desarrollo por la banca estatal china (Banco de Desarrollo de China y Export-Import Bank de China) sumaron USD 524 mil millones ("China development banks expand links with foreign lenders", 2018), mientras que los desembolsados por el FMI, el Bм y su red multilateral regional fueron de USD 489 millardos, representando los créditos chinos más de la mitad de la financiación mundial para naciones en desarrollo aportada por la banca para el desarrollo $^{18}$ (se incluyen préstamos soberanos y no soberanos). Otras instituciones de banca multilateral sumaron USD 17 millardos, incluyendo al Banco Islámico (fundado en 1975) y dos nuevas instituciones: el Banco de países Bric ${ }^{19}$ (Nuevo Banco para el Desarrollo — NBD-) y el Banco Asiático de Inversión e Infraestructura (BAII).

Banco Asiático de Infraestructura; los BRIC: Banco de los BRIC; BD China: Banco de Desarrollo de China; ExImB Ch: Banco de Expo-Impo de China.

18 No se incluye en esta al Banco Europeo de Inversiones, debido a que concentra su cartera en la Unión Europea y Europa, aunque presta marginalmente en otros continentes. Para diciembre del 2018 tenía una cartera desembolsada de 431 mil millones EUR.

19 Brics: grupo de países compuesto por Brasil, Rusia, India, China y Suráfrica. 
Los grandes recursos prestados por los bancos chinos se han destinado a inversiones y proyectos de desarrollo que este país tiene en todos los continentes. De forma paralela, China está realizando grandes esfuerzos por crear una nueva banca multilateral a través de nuevas instituciones con socios de otras naciones, especialmente asiáticas, en las cuales los derechos de voto no estén controlados por EE. UU., Europa y Japón. En el BAII, creado en el 2013 con sede en Beijing y que inició operaciones comerciales en el 2016, sus 97 socios han convenido un capital suscrito de USD 100 millardos, de los cuales se habían pagado USD 19,5 millardos en diciembre del 2018. Sus principales socios se aprecian en la figura 8, así como también los principales aportantes del NBD, los miembros del tradicional Banco de Desarrollo del Asia (BDA) y del Banco Interamericano de Desarrollo (BID).
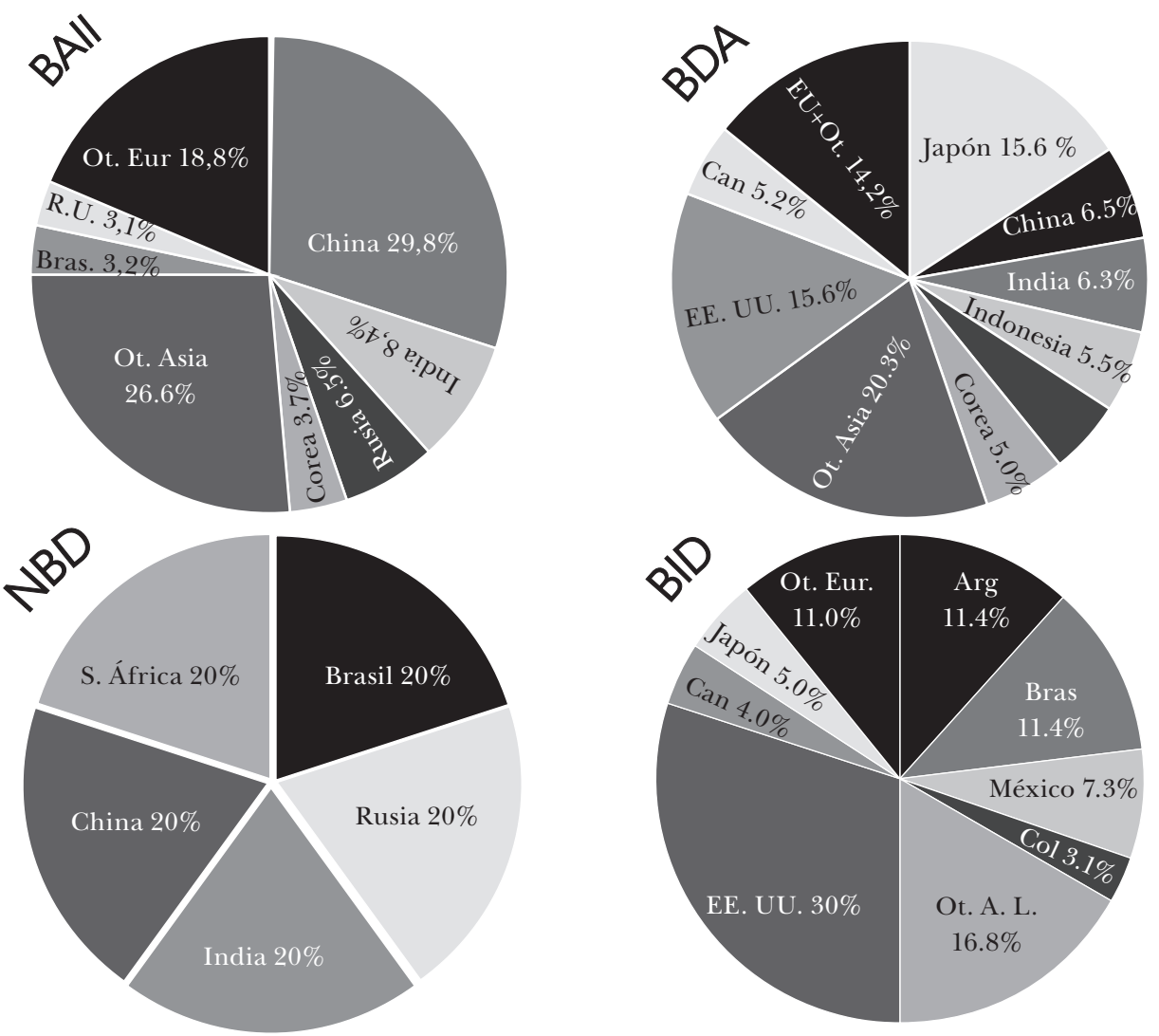

Figura 8. Capital suscrito por la banca multilateral para el desarrollo. Fuentes: informes anuales 2017 y 2018 de bancos.

NBD, cuya sede principal está en Shanghai (China), inició operaciones en el 2016 y tiene un capital autorizado de UsD 50 mil millones, de los 
cuales debe aportar cada miembro igualitariamente UsD 10 milllardos, con un plazo de pago hasta el 2023. Con este banco y el BAII —que también inició operaciones en el 2016-, la banca multilateral que financia a países en desarrollo sienta las bases para crecer sustancialmente, caracterizándose por haber incluido dentro de sus estatutos el no condicionamiento de las políticas internas de los países que han de utilizar sus recursos, aspecto de gran importancia que busca superar los condicionamientos que tradicionalmente han practicado las instituciones emanadas de Bretton Woods. Ahora China y otras naciones asiáticas cuentan con mayorías que pueden decidir sobre políticas y financiación de proyectos específicos en muchas naciones del globo, factor que puede influir en la reducción del tradicional condicionamiento de la banca multilateral. Como se aprecia en las composiciones de capital de los dos nuevos bancos, las mayorías, con su capacidad de voto, están entre China y Asia (para el BAII) o distribuida equitativamente (NBD). Tanto EE. UU. como Japón declinaron participar en el BAII, mientras que en el NBD se restringió su capital a los cinco países miembros del grupo.

Un tercer (potencialmente) gran banco multilateral cuya acta de creación se firmó en la Casa Rosada de Buenos Aires en el 2007 es el Banco del Sur, que posee un capital autorizado de usD 20 millardos, y está conformado por Brasil, Argentina y Venezuela (con un 28,75\% cada uno), y Ecuador, Uruguay, Bolivia y Paraguay (el 14,3\% restante). Sin embargo, la iniciativa política de presidentes de izquierda como Ignacio Lula Da Silva (Brasil), Néstor Kirchner (Argentina) y Hugo Cháves (Venezuela) ha perdido a la fecha respaldo entre sus sucesores o padece una grave crisis (Venezuela), haciendo que este banco multilateral suramericano con sede en Caracas no despegue hasta el presente.

La creación de una banca multilateral no controlada por las potencias que firmaron el acuerdo de Bretton Woods aumenta la autonomía para cofinanciar nuevos grandes proyectos en países en desarrollo, y se suma a los recursos disponibles en la banca multilateral tradicional y a la creciente captación de recursos privados para canalizar hacia proyectos de infraestructura. Dentro de estos macroproyectos, la Iniciativa de la Nueva Ruta de la Seda (NRS), propuesta por China en el 2013, constituye una enorme posibilidad para dinamizar la inversión en infraestructura, el intercambio comercial y tecnológico entre numeros países en vías de desarrollo del Asia, que los integrará mejor a la economía mundial y los comunicará por tierra con Europa, y por mar con Oceanía, África y América. 


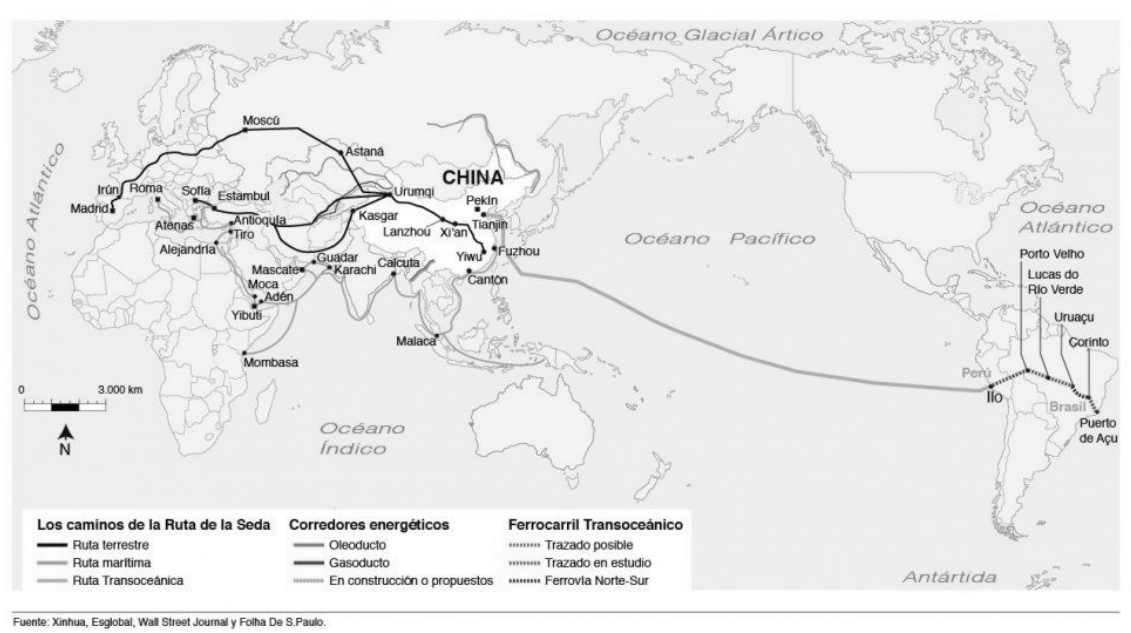

Figura 9. La Ruta de Seda en el siglo xxI.

Fuente: Higueras (2015).

La NRS es un ambicioso plan a largo plazo liderado por el gobierno chino, que contempla inversiones en infraestructura por cientos de miles de millones de dólares. Este es un plan internacional de inversiones de tal magnitud, que no se proponía algo similar desde el Plan Marshall de EE. UU. al finalizar la Segunda Guerra Mundial. China espera resolver problemas internos tales como jalonar áreas poco desarrolladas del norte y noroeste, ampliar su mercado interno en tiempos de reducción del ritmo global de comercio, redirigir sus excesos de capacidad industrial instalada, así como promover su liderazgo tecnológico (Cai, 2017; Manzoor, Wei, Latif, \& Shah, 2017). No obstante, el plan además exige cuantiosas inversiones internacionales para poder ser una realidad que interconecte mejor gran parte del planeta. Para comprender la magnitud de este, se describen a continuación sus principales componentes.

Las obras empiezan en la zona costera china (provincias de Fujian y Zhejiang) y se conectan por tierra con sus regiones menos avanzadas del norte y noroccidente (provincias de Gansu y Xinjiang), a través de las cuales hacen contacto con países del Asia Central que han estado parcialmente embotellados (antiguas áreas con población musulmanana del Imperio Otomano, y luego parte de la Unión Soviética, Kasajistán, Kirguistán, Tajikistán, Uzbekistán), países con importantes reservas de gas, petróleo y minerales. A partir de estos, varios corredores conectarán 
por tierra a China con Pakistán y el mar Arábigo (abriendo una ruta alternativa al congestionado paso marítimo del estrecho de Malaca en Singapur). Otra ruta pasa por Irán, el Medio Oriente, Turquía y finalmente llega por el suroriente de Europa a Austria. Por el norte, las vías férreas y carreteras conectarán con la Rusia asiática y Moscú, llegando luego a través de varias rutas hasta diferentes países del centro, norte y occidente de Europa. Algunas de estas rutas ya existen, pero sus estándares deben actualizarse a las exigencias del comercio internacional actual, mientras otras son totalmente nuevas. La conexión por ferrocarril entre la costa china (desde Yiwu, provincia de Zhejiang) y Londres (Inglaterra) ya inició su primer viaje el 1..$^{\circ}$ de enero del 2017 ("El ambicioso proyecto detrás del tren que une por primera vez China y Reino Unido y qué dice de la economía del gigante asiático”), recorriendo $12.000 \mathrm{Km}$ en 18 días. Este pasa por Kazakistán, Moscú, Rusia Blanca y Alemania, desde donde las rutas se bifurcan hacia Italia, Francia, Inglaterra y la península ibérica, constituyéndose en una alternativa de costo y tiempo intermedios a los transportes por mar y aire.

También se realizan obras y se firman acuerdos para desarrollar el corredor del Sudeste Asiático, que comunicará el suroccidente de China (provincia de Yunnan), desde la ciudad de Kumming a través de la cuenca del río Mekong, con países de la Comunidad Económica del Sureste del Asia (Asean) hasta llegar a Bangkok (Tailandia), la península malaca y las islas indonesias. Esta región presenta una gran actividad comercial con China y está integrada a cadenas industriales de valor con todo el mundo ${ }^{20}$. Adicionalmente el corredor marítimo, o la Ruta de la Seda Marítima, concibe nueva infraestructura para unir mejor los puertos chinos con las cuencas del Pacífico, Australia y Oceanía, así como con las regiones árabes del Medio Oriente, los puertos y el interior del continente africano. A través del canal de Suez estas rutas marítimas se comunicarán con la Europa mediterránea (vía El Pireo, Atenas, en Grecia, y Venecia, en Italia), desde donde se conectan por tierra con el resto de Europa.

Incluso existe en la NRS un macroproyecto con América del Sur, en el cual los gobiernos de Perú y Chile están interesados en constituirse

20 China ganó la licitación para construir el ferrocarril de alta velocidad entre Jakarta y Bandung (Indonesia), de $142 \mathrm{Km}$. Otro macroproyecto que avanza al presente es la construcción del ferrocarril de la costa este de Malasia, cuyo valor inicial se pactó en Ringgit en 65 millardos, el cual debió renegociarse con acuerdo cerrado en abril del 2019 entre las autoridades malayas y chinas, lo que redujo la inversión a Ringgit 44 millardos (USD 10,4 millardos). Véase ("Xi Jinping's Second Belt and Road Forum: Three Key Takeaways”, 2019). 
como una entrada del océano Pacífico que conectaría por tren al océano Atlántico en Brasil, pasando por Bolivia y áreas de gran producción de soya, trigo, carne y otros recursos. Una característica geopolítica muy especial de la NRs es que, para salir de China, necesariamente tienen que construirse miles de kilómetros de infraestructura en países limítrofes de menor desarrollo económico, constituyéndose en un enorme frente de nuevas inversiones e intercambios que pueden dinamizar grandes áreas en vías de desarrollo del planeta, con la posibilidad de mejorar la equidad en muchos de estos países.

Este gigantesco plan ya inició a su etapa de construcción: su primer gran paso integral es el Corredor de Pakistán, que atraviesa de norte a sur este país y conduce al mar Arábigo: desde la ciudad china de Kashgar (Xinjiang) se están bordeando los Himalaya por el noroeste con vías de tren, carreteras y redes eléctricas, hasta terminar al sur en el nuevo puerto de aguas profundas en Gwadar, cerca de la frontera con Irán. Este corredor reduce en cerca de $5.000 \mathrm{Km}$ la distancia al mar desde el noroeste de China (Manzoor et al., 2017, p. 423) e interconecta Pakistán a través de la cuenca del río Indo - una importante zona de producción de cereales-, que ahora podrá tener salida por el norte hacia China y Asia central. Los gobiernos de China y Pakistán reportan una inversión de usD 57 millardos, que incluyen $3.000 \mathrm{Km}$ de carreteras y vías férreas, 16.500 megavatios de nueva potencia eléctrica (similar a la total instalada en Colombia actualmente), que permita superar los constantes apagones actuales en ese país, así como la construcción de una refinería de petróleo ${ }^{21}$ y un gran puerto en Gwadar, entre otros macroproyectos que se espera concluyan en el 2030 con la financiación del Export-Import Bank de China, el New Development Bank de China, el Banco Asiático de Inversión en Infraestructura y el Banco Islámico, entre otros (Manzoor et al., 2017, p. 420$)^{22}$.

21 La prensa internacional reportó el 19 de febrero del 2019 que en la reciente visita del príncipe heredero de Arabia Saudita, Mohammed bin Salman en Islamabad, su país invertirá usd 8 millardos en esta refinería. Por su parte, China ofrecerá usD 6 millardos además de una inversión de los Emiratos Árabes Unidos (“Saudi Arabia Is Investing \$20 Billion in Pakistan. Here's What It's Getting in Return”, 2019).

22 El presidente del Banco Islámico (IDB), Bandar Hajjar, declaró el 20 de febrero del 2018: "We will partner with the AIIB/BAII", said in an interview with the Financial Times. "We will co-finance many projects [with AIIB] in the future in África. África needs... about $\$ 150 \mathrm{bn}$ a year to finance infrastructure and there are about $650 \mathrm{~m}$ people in África without access to electricity'. Cooperation between the AIIB and the IDB, which are capitalised at $\$ 100 \mathrm{bn}$ and $\$ 150 \mathrm{bn}$ respectively, is set to create a new force in development finance for a swath of developing countries. Many of the IDB's 57 member countries overlap with the AIIB's approved membership of some 80 nations. 
Un importante instrumento de la arquitectura financiera que soporta la NRs es el Fondo para la Ruta de la Seda (Silk Road Fund, en inglés), creado en diciembre del 2014 por el gobierno chino en Beijing. Su capital inicial fue de USD 40 millardos, compuesto por aportes estatales de la Administración China de Moneda Extranjera (65\%), la Corporación de Inversiones de China, el Banco de Exportación e Importación y el Banco de Desarrollo de China (Silk and Road Fund, s. f.). El Fondo está firmando acuerdos para canalizar fondos de multitud de otros inversionistas, tanto estatales como privados, así como para seleccionar programas de inversión en numerosos países del globo. En abril del 2019 el presidente chino Xi Jinping convocó el Segundo Foro de la NRs en Beijing. La Agencia de Noticias Bloomberg reportó con respecto al aumento de financiación del Fondo y los nuevos socios de la iniciativa NRs:

(President) Xi... said USD 64 billion worth of deals were signed at last week's forum. In 2017, he said China would add 100 billion yuan (USD 14.8 billion) to the Silk Road Fund and two state-owned banks would provide special loans for BRI (NRS) projects worth 380 billion yuan (USD 56 mil millones) in total... In March (2019), Italy became the first "Group of 7" country to sign up for the BRI, a big win for Beijing that also raised alarm bells in the region. At last week's forum, developed countries including Austria, Switzerland and Singapore signed up for so-called third-party market cooperation. Japan, France, Canada, Spain, the Netherlands, Belgium, Italy and Australia have already signed the document, agreeing to help build infrastructure in developing countries ("Xi Jinping‘s Second Belt and Road Forum: T hree Key Takeaways").

Las primeras inversiones de este fondo se han destinado a la construcción de hidroeléctricas en Pakistán, inversiones petroquímicas en Dubai y Rusia, y la financiación de la construcción de la línea férrea entre Nairobi y el puerto de Mombasa, en Kenia (África). La moderna vía de $485 \mathrm{Km}$ conecta a la capital con el puerto sobre el mar Índico. Trabajaron en su construcción 25.000 kenianos; se inauguró el 1. de enero del 2018, y mueve cuatro rutas diarias de pasajeros y 30 de carga. La continuidad de esta ruta, siguiendo las antiguas vías construidas por Gran Bretaña, permitirá conectar otros países centroafricanos en dirección a Uganda. Su financiación se realizó en un 90\% por el Export-Import Bank de China, dentro de su aporte al Fondo NRs. 
Es indudable que una iniciativa de inversiones tan ambiciosa e impactante como la NRs - para, preferentemente, países en desarrollorequerirá ejecutar durante los próximos años la mayor tarea de construcción y financiación que se haya conocido en el planeta. La NRS ya empezó y el gobierno chino está organizando tanto una nueva infraestructura financiera propia, como invitando a sus socios del Asia —estatales y privados—, así como a inversionistas de todo el globo, para que coadyuven a hacer realidad los proyectos. Estos avanzan en Asia y África, atrayendo flujos financieros inéditos que generan gran cantidad de empleos, realizaciones tecnológicas, integración entre personas y naciones, catapultando el desarrollo de una banca multilateral que se está poniendo al día con las necesidades de crecimiento y equidad de los países en desarrollo. Dada la negativa de los EE. UU. de participar en esta macroiniciativa hasta el momento, la financiación y el liderazgo chinos crecerán, junto con el apoyo de otras naciones del Asia, Europa y el globo. Algo muy significativo es que este liderazgo está apoyado en el crecimiento de la economía "real” (infraestructura), mas no en la especulación financiera que se ha apoderado de grandes circuitos de la economía mundial (Gómez-Jiménez, 2010).

\section{Consideraciones finales}

- Se puede colegir que las instituciones creadas por el consenso de Bretton Woods en 1944 - y particularmente las de orden financieroprestaron un valioso apoyo para reconstruir las economías del mundo desarrollado luego de la Segunda Guerra Mundial. Igualmente se habilitaron mecanismos que hicieron más fácil el comercio y la irrigación amplia de tecnologías modernas, lo que permitió un mayor acceso de las poblaciones del planeta para mejorar sus niveles de vida, aún a pesar de los usuales condicionamientos políticos de estas instituciones.

- Con el correr del tiempo, los conflictos y recurrentes episodios de crisis financieras globales y regionales muestran que la gobernanza mundial sigue requiriendo de instituciones internacionales fuertes y consultivas. Sin embargo, el sistema de liderazgo vigente encabezado por EE. UU. es cuestionado por su propio líder, lo que ocasiona traumatismos en diferentes contextos y anunciando al resto de la comunidad internacional que es necesario trabajar en la ampliación 
de un liderazgo global de tipo más plural. La reticencia del presidente Trump a ejercer un liderazgo internacional más consultivo, menos confrontacional, no solo parece expresar el declive relativo del poder económico de su país, expresado en sus crónicos déficits fiscal y comercial, sino que aparece como una oportunidad para que se refuercen las iniciativas de otras naciones, quienes con visiones más inclusivas, puedan apoyar políticas que posibiliten una comunidad internacional más democrática y sustentable, menos especulativa y depredadora de los recursos naturales: un mundo más multipolar, pacífico y equilibrado.

- Parte de la comprensión y superación de la crisis del 2008 pasa por el reconocimiento de la limitada capacidad de la institucionalidad financiera emanada de los acuerdos de Bretton Woods, ya que se requiere de muchos más recursos para apoyar el desarrollo global a través de la construcción de infraestructura que eleve el nivel de vida en los países en desarrollo. Esta banca está exigiendo más capacidad crediticia, la que está siendo aportada por China a través de sus bancos para el Desarrollo y del Fondo para la Nueva Ruta de la Seda, como se muestra en este trabajo. Pero adicionalmente este país está jalonando la creación de nueva infraestructura financiera adicional y potente, a través del Banco Asiático de Inversión e Infraestructura y del Banco BRIC, invitando no sólo a los países del Asia, sino de todo el globo, con recursos estatales y privados.

- Diferentes naciones de Europa, de países Islámicos, de los BRIC y de otras regiones están ya vinculándose al proceso de financiación requerido por la iniciativa de la NRS, macroproyecto jalonado por China, pero que tiene impacto global. La construcción de la NRs tiene la potencialidad de ofrecer un oxigenante horizonte a la economía mundial, a través de la inversión en obras reales de infraestructura principalmente en países en desarrollo (aunque no exclusivamente), las cuales trascienden las iniciativas especulativas que han estado dominando las finanzas del globo. La NRs ya inició su construcción integral a través del Corredor de Pakistán, indicando al mundo un camino de trabajo pacífico, con grandes retos y potencial de participación. Alrededor de este enorme proyecto se pueden gestar las condiciones para transformar el liderazgo global en un futuro próximo.

- Ante la reversa globalizadora que está propiciando el presidente Trump, paralelamente está emergiendo China como un jalonador 
del desarrollo mundial. Su visión está más ligada a proyectos reales y pacíficos que rápidamente impactan muchas naciones, sectores sociales y económicos del mundo desarrollado y en desarrollo, lo que auspicia el crecimiento de una banca multilateral más poderosa y capaz de unir la voluntad de diversas naciones del planeta, incluídas las europeas y Japón, dinámica que en su devenir sin duda ampliará los espacios de participación y de gobernanza más inclusiva y democrática que la concebida a mediados del siglo xx en Bretton Woods.

\section{Referencias}

Acharya, A. (2017). After liberal hegemony: The advent of a multiplex world order. Ethics $\mathcal{E}$ international affairs, 31(3), 271-285.

African Development Bank (2018). Annual Report. Recuperado de www.afdb.org. Amín, S. (1994). El fracaso del desarrollo en África y en el tercer mundo: un análisis político. Edit. Madrid: Iepala

Alagiri, D. (Ed.). (2006). Financial Growth in India and China: A Comparative Study. Hyderabad: ICFAI University Press

Asian Development Bank. (2018). Annual Report. Recuperado de https://www.adb. org/documents/adb-annual-report-2018.

Banco Centroamericano de Integración Económica. (2018). Informe anual 2018. Recuperado de https://www.bcie.org/relacion-con-inversionistas/estadosfinancieros/

Banco Interamericano de Desarrollo (BID). (2018). Reporte anual 2018. Recuperado de https://publications.iadb.org/es/banco-interamericano-de-desarrolloinforme-anual-2018-estados-financieros

Bolt, P. (2015). US, Chinese, and Russian Perspectives on the Global Order. Air Force Academy. Recuperado de https://apps.dtic.mil/dtic/tr/fulltext/u2/1013428. pdf.

BRIC Bank. (2018). Annual Report 2018. Recuperado de https://issuu.com/ bricartsmedia/docs/bric_annualreport18_final_web_widge

Bundesministerium von Finanzen (BMF) und Bundesministerium fuer Zussammenarbeit (BMZ). (2004). Jahre Bretton Woods-Institutionen:

Standortbestimmung und Ausrichtung. Berlin: BмF und BMZ.

Buchner, T. (2008). Die Geschichte der Globalisierung. Berlin: Friedrich Ebert Stiftung

Cai, P. (2017). Understanding China's Belt and Road Iniciative. Ciudad: Lowy Institute for International Policy.

Chang, H. J. (2003). Kicking away the ladder: development strategy in historical perspective. London: Anthem Press. https://doi. org/10.1108/10748120510618222

China development banks expand links with foreign lenders. (2018, 15 de julio). Financial Times. 
El ambicioso proyecto detrás del tren que une por primera vez China y Reino Unido (y qué dice de la economía del gigante asiático). (2017). BBC. Recuperado de https://www.bbc.com/mundo/noticias-38501293

El Banco Mundial aprueba dar más peso a los países emergentes y una ampliación de capital. (2010, 25 de abril). El Mundo. Recuperado de https://www. elmundo.es/mundodinero/2010/04/25/economia/1272218488.html

El Banco Mundial reconoce que perjudicó a Chile alterando el índice de competitividad. (2018, 13 de enero). Última Hora. Recuperado de https:// www.ultimahora.es/noticias/internacional/2018/01/13/320169/bancomundial-reconoce-perjudico-chile-alterando-indice-competitividad.html

El liderazgo de Estados Unidos en el Banco Mundial. (2019, 26 de abril). Comité para la abolición de las deudas ilegítimas. Recuperado de http://www.cadtm. org/El-liderazgo-de-Estados-Unidos-en-el-Banco-Mundial

Export-Import Bank of China. (2018). Annual Report 2018. Recuperado de https://www.exim.gov/sites/default/files/reports/annual/2018/EXIMAnnualReport-2018.pdf

European Investment Bank (2018). Annual Report 2018. Recuperado de https:// www.eib.org/en/publications/financial-report-2018

Federal Reserve Bank (FED). (2018). U.S. Corporations' Repatriation of Offshore Profits. FEDS Notes. https://doi.org/10.17016/2380-7172.2239

Gómez-Jiménez, A. G. (2010). El relevo hegemónico, la crisis económica mundial y la actual revolución tecnológica en perspectiva histórica. Ensayos de Economía, 19(34), 47-83.

González-Sáez, R. (2018). Las relaciones económicas China-Estados Unidos: entre la independencia y la confrontación. Asia-América Latina, 3(5).

Hamilton, D. S. (2017). Trump's Jacksonian Foreign Policy and its Implications for European Security. UI Brief, 2.

Higgott, R. (2017). Globalism, populism and the limits of global economic governance. Journal of Interegional Studies: Regional and Global Perspectives, from March, 2-23.

Higueras, G. (2015). La Ruta de la Seda del siglo xxi. Estudios de Política Exterior, (167). Recuperado de http://www.politicaexterior.com/articulos/politicaexterior/la-ruta-de-la-seda-del-siglo-xxi/

IMF Members' Quotas and Voting Power, and IMF Board of Governors. (2017, 15 de mayo). Recuperado de www.imf.org

Islamic Development Bank (2018). Annual Report. Recuperado de https://www. isdb.org/sites/default/files/media/documents/2019-04/usb\%20Annual\%20 report $\% 20$ English $\% 20$

Jones, D. M., \& Khoo, N. (2017). Donald Trump and the new Jacksonians. Policy: A Journal of Public Policy and Ideas, 33(1), 42.

Kramer, M. (2012). The Demise of the Soviet Bloc. En V. Tismaneanu, The End and the Beginning: The Revolutions of 1989 and the Resurgence of History. Budapest: Central European University Press. 
List of countries by foreign-exchange reserves. (s. f.). Wikipedia. Recuperado de https://en.wikipedia.org/wiki/List_of_countries_by_foreign-exchange_ reserves

Magness, P. (2018). Donald Trump, Hamiltonian. Recuperado de http://philmagness. $\mathrm{com} /$ ? $\mathrm{p}=1775$

Mahtaney, P. (2007). India, China and Globalization. The Emerging Superpowers ant the Future of Economic Development. New York: Palgrave MacMillan.

Manzoor, F, Wei, L., Latif, A., \& Shah, S. (2017). A review on one belt one roadChina Pakistan economic corridor and its policy implications. Second International Conference on Economic and Business Management (FEBM 2017).

Advances in Economics, Business and Management Research, volume 33. https://doi.org/10.2991/febm-17.2017.5 $\underline{5}$

Marsh, P. (2012). The New Industrial Revolution. Consumers, Globalization and The End of Mass Production. New Haven and London: Yale University Press.

New Development Bank. (2018). Annual Report 2017. Recuperado de https://www. ndb.int/data-and-documents/annual-reports/

Pigrau, A. (1996). Las políticas del FMi y del banco mundial y los derechos de los pueblos. Afers Internacionals, (29-30), 139-175.

Ocampo, J. A. (2005). Más allá del Consenso de Washington: una agenda de desarrollo para América Latina. Ciudad de México: Cepal.

Palma, J. G. (2005). Flying-geese and waddling-ducks: the different capabilities of East Asia and Latin America to 'demand-adapt' and 'supply-upgrade' their export productive capacity. Cambridge: University of Cambridge.

Peterson Institute for International Economics (PIIE). (2018). Trump Tariffs Primarily Hit Multinational Supply Chains, Harm US Technology Competitiveness.

Saudi Arabia Is Investing \$20 Billion in Pakistan. Here's What It's Getting in Return. (2019, 19 de febrero). Time. Recuperado de https://time. com/5531724/saudi-arabia-pakistan-mbs-imran-khan/

Silk and Road Fund. (s. f.). Recuperado de www.silkroadfund.com.cn/enweb

Shafaeddin, M. S. (2005). Trade liberalization and economic reform in developing countries. The IMF, World Bank and Policy Reform, 155, 2-20.

Stiglitz, J. (2003). Globalization and its Discontents Revisited. Antiglobalization in the Era of Trump. New York: Norton \& Co.

Thakur, R. (2011). The United Nations in global governance: Rebalancing organized multilateralism for current and future challenges. Thematic Debate on Global Governance, General Assembly, United Nations, New York.

The full text of Donald Trump's inauguration speech. (2017, 20 de enero). The Guardian.

Torres-González, J. (2016). El Reto de las Exportaciones de China para los Países en Desarrollo. Revista Análise Econômica, (34)65, 345-377. https://doi. org/10.22456/2176-5456.51522

U.S. Budget Deficit by Year Compared to GDP, Debt Increase, and Events. (2019, 25 de junio). The Balance. Recuperado de https://www.thebalance.com/usdeficit-by-year-3306306 
Van Ham, Peter. (2018). Trump's Impact on European Security: Policy Options in a PostWestern World. Clingendael: Netherlands Institute of International Relations.

Ventas de empresas de EE. UU. a China. (2018, 22 de junio). Portafolio.

Voutsa, M. \& Borovas, G. (2015). The role of the Bretton Woods institutions in global economic governance. Procedia Economics and Finance, 19, 37-50. https://doi.org/10.1016/S2212-5671(15)00006-4

World Bank. (2017). IBRD Country Voting Table. Recuperado de http:// siteresources.worldbank.org/BODINT/Resources/278027-1215524804501/ IBRDCountryVotingTable.pdf Consultada el 28.07.2017

Xi Jinping،s Second Belt and Road Forum: Three Key Takeaways. (2019). Bloomberg. Recuperado de https://www.bloomberg.com/news/articles/2019-04-28/xijinping-s-wins-and-losses-at-his-second-belt-and-road-forum 